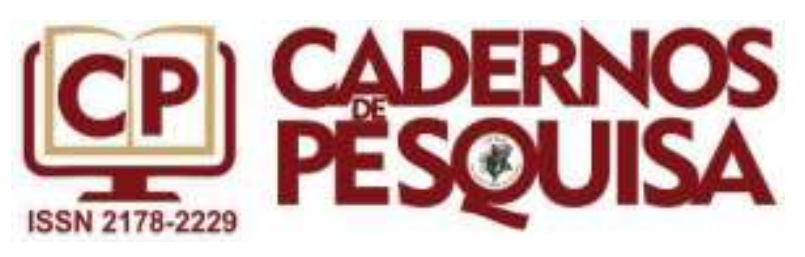

\title{
ATRAVESSAMENTOS DA PANDEMIA DE COVID-19 NA EDUCAÇÃO ESCOLAR BRASILEIRA
}

\author{
ADVENTURES OF THE COVID-19 PANDEMIC IN BRAZILIAN \\ SCHOOL EDUCATION
}

\section{CRUCES DE LA PANDEMIA COVID-19 EN LA EDUCACIÓN ESCOLAR BRASILEÑA}

\author{
Fernanda Monteiro Rigue ${ }^{1}$ \\ ORCID: http://orcid.org/0000-0003-2403-7513 \\ Gilberto Oliari² \\ ORCID: https://orcid.org/0000-0003-3102-8383 \\ Raquel Brum Sturza ${ }^{3}$ \\ ORCID: https://orcid.org/0000-0002-8229-9178
}

\begin{abstract}
Resumo: $O$ presente artigo tem por objetivo compreender ' $\mathrm{O}$ que pode a educação escolar em tempos de pandemia de COVID-19?'. Para tanto, a pesquisa teórico-empírica de caráter qualitativo (DENZIN; LINCOLN, 2006) foi esboçada por meio de um instrumento que é o formulário online, contendo um conjunto de quinze questões, contendo perguntas fechadas e abertas. Os achados da pesquisa foram explorados por meio de análise de conteúdo (BARDIN, 2004), tendo como inspiração teórico-epistemológica os escritos de Deleuze (1992; 2000), Guattari e Rolnik (1996), Rolnik (2018), Foucault (2000; 2008), Rouvroy e Berns (2010; 2015) e Corrêa (2006). Resultou da pesquisa a compreensão da pandemia como um acontecimento (DELEUZE, 1992, 2000), que emerge em meio a um cenário de governamentalidade algorítmica (ROUVROY; BERNS, 2010), o qual vincula-se a um agenciamento de subjetividade capitalística (ROLNIK, 2018). Emerge da pesquisa a compreensão de que a pandemia colocou em ênfase esse movimento de controle, individualização e comunicação (CORRÊA, 2006) que já vinha crescendo, como elementos de um contexto neoliberal, o qual, visto sob o prisma da educação escolar, vem produzindo ainda mais afetos, efeitos e sintomas sob as vidas e corpos das pessoas vinculadas de algum modo, às instituições de ensino. O quanto as estratégias de ensino empregadas em tempos de pandemia têm contribuído para um aumento massivo de sofrimento psíquico, em meio a um contexto de distanciamento social, já que boa parte delas utilizam premissas do ensino presencial. Palavras-chave: subjetividade capitalística. pandemia. educação escolar.
\end{abstract}

1 Universidade Federal de Uberlândia (UFU). Ituiutaba - MG, Brasil.

2 Universidade Federal de Santa Maria (UFSM). Chapecó - SC, Brasil.

3 Universidade Federal de Santa Maria (UFSM). Santa Maria - RS, Brasil. 
Abstract: The present article aims to understand 'What can school education do in times of the COVID-19 pandemic?' To this end, the theoretical-empirical research of qualitative nature (DENZIN; LINCOLN, 2006) was outlined by means of an instrument that is the online form, containing questions a set of fifteen questions, containing closed and open questions. The research findings were explored through content analysis (BARDIN, 2004), taking as theoretical-epistemological inspiration the writings of Deleuze (1992, 2000), Guattari and Rolnik (1996), Rolnik (2018), Foucault (2000, 2008), Rouvroy and Berns (2010, 2015), and Corrêa (2006). Resulting from the research, is the understanding of the pandemic as an event (DELEUZE, 1992, 2000), which emerges amidst a scenario of algorithmic governmentality (ROUVROY; BERNS, 2010), which links to an agency of capitalistic subjectivity (ROLNIK, 2018). It emerges from the research, the understanding that the pandemic has emphasized this movement of control, individualization, and communication (CORREA A, 2006). That we had already been growing, as elements of a neoliberal context, which, seen from the perspective of school education, has been producing even more affections, effects, and symptoms on the lives and bodies of people, somehow linked to educational institutions. The teaching strategies employed in times of pandemic have contributed to a massive increase in psychological suffering, in the midst of a context of social distance, since most of them use premises of classroom teaching.

Keywords: capitalistic subjectivity. pandemic. school education.

Resumen: Este artículo pretende comprender '¿Qué puede hacer la educación escolar en tiempos de la pandemia COVID-19?'. Para eso, la investigación teórico-empírica de carácter cualitativo (DENZIN; LINCOLN, 2006) se bosquejó a través de un instrumento que es el formulario en línea, que contiene preguntas, un conjunto de quince preguntas, que contiene preguntas cerradas y abiertas. Los resultados de la investigación fueron explorados a través del análisis de contenido (BARDIN, 2004), teniendo como inspiración teórica y epistemológica los escritos de Deleuze (1992; 2000), Guattari y Rolnik (1996), Rolnik (2018), Foucault (2000; 2008), Rouvroy y Berns (2010; 2015) y Corrêa (2006). La investigación resultó en la comprensión de la pandemia como un evento (DELEUZE, 1992, 2000), que surge en medio de un escenario de gubernamentalidad algorítmica (ROUVROY; BERNS, 2010), que está vinculado a una agencia de subjetividad capitalista (ROLNIK, 2018). De la investigación surge el entendimiento de que la pandemia enfatizó este movimiento de control, individualización y comunicación (CORRÊA, 2006) que ya estaba creciendo, como elementos de un contexto neoliberal, que, visto desde la perspectiva de la educación escolar, ha ido produciendo aún más afectos, efectos y síntomas en la vida y el cuerpo de personas vinculadas de alguna forma a instituciones educativas. Cuánto las estrategias de enseñanza utilizadas en tiempos de pandemia han contribuido a un aumento masivo de la angustia psicológica, en medio de un contexto de distanciamiento social, ya que la mayoría de ellas utilizan premisas de la enseñanza en el aula.

Palabras clave: subjetividad capitalista. pandemia. enseñanza.

\section{INTRODUÇÃO}

Historicamente, a humanidade foi deveras afetada por uma série de doenças ${ }^{4}$ (transmissíveis e não transmissíveis), que atravessaram diferentes compreensões de saúde e, ao mesmo tempo, das respectivas noções e tecnologias empregadas nos sistemas de saú$\mathrm{de}^{5}$ (indústrias das vacinas, medicamentos, entre outros), públicos e privados, acarretando

\footnotetext{
4 Trata-se de uma condição, de caráter anormal, que produz efeitos negativos no organismo e/ou estrutura de alguma parte do corpo do ser humano.
}

5 Como é o caso do Sistema Único de Saúde (SUS) criado em meados de 1990. 
muitas mudanças no modo de vida das pessoas, comunidades e nações. Essas mudanças aconteceram/acontecem muitas vezes de forma drástica, tendo em vista que aparecem compulsoriamente, nos situando em uma realidade que jamais pensaríamos viver. De uma hora para outra, as pessoas se percebem tendo que mudar seus hábitos, seu modo de se relacionar com os demais, suas particularidades no modo de realizar ações corriqueiras - como ir ao banco ou ao supermercado - e, até mesmo, a transformar o seu modo de formação educacional e escolar. O que permite corroborarmos com Michel Foucault (1999), quando considera que as discussões biológicas passaram a atuar no centro da vida a partir da modernidade, contingenciando que os sujeitos respondam ativamente a essas mudanças, o que acontece de modo muito específico e heterogêneo.

No caso das doenças transmissíveis, em se tratando da epidemiologia, muitas foram as doenças já catalogadas, "A distribuição, no espaço e no tempo, das doenças e dos agravos em geral mereceu desde sempre a atenção da área da saúde" (CARVALHEIRO, 2008 , p. 11). Por sua vez, algumas doenças emergem em meio a condições propícias de desenvolvimento e proliferação, situando os indivíduos e grupos em contingências difíceis. Em se tratando do alastramento e mobilidade geográfica de epidemias, por meio de indivíduos infectados, podemos verificar a emergência das pandemias, que por vezes estão vinculadas a novas mutações e subtipos. Conforme apontam Luna e Silva Jr. (2013):

[...] o surgimento de novos problemas de saúde relacionados a novos agentes infecciosos; e a mudança de comportamento epidemiológico de velhas doenças infecciosas, incluindo a introdução de agentes já conhecidos em novas populações de hospedeiros suscetíveis e outras alterações importantes no seu padrão de ocorrência. Esses fenômenos da emergência e reemergência de doenças infecciosas estão relacionados a diversos fatores, desde as profundas e rápidas mudanças que têm ocorrido em aspectos demográficos, socioeconômicos e ambientais, além daqueles relacionados ao desempenho do setor saúde, das mudanças e mutações nos microrganismos, até a possibilidade de manipulação de agentes infecciosos com vistas ao desenvolvimento de armas biológicas (p. 123).

Em se tratando do Brasil, Luna e Silva Jr. (2013) apontam que dentre as pandemias que já afetaram a humanidade, uma delas a A/H1N1 pdm - Influenza pandêmica foi abordada da seguinte forma pelo país, em contraste com o Chile, por exemplo:

O país adotou uma definição de casos suspeitos de maior gravidade, a Síndrome Respiratória Aguda Grave (SRAG), e passou a orientar as ações de vigilância e controle prioritariamente para este grupo de pacientes. Quase 50 mil casos de SRAG pelo vírus pandêmico foram confirmados, com mais de 2 mil óbitos. A taxa de mortalidade observada na Região Sul foi de 2,3 por 100.000 hab., três vezes maior que a registrada no Chile, de apenas $0,8 / 100.000$ hab., provavelmente pelas diferenças de abordagens em relação ao tratamento com o antiviral oseltamivir, que teve estratégias radicalmente diferentes entre os dois países. Enquanto o Chile adotou o tratamento imediato de todos os casos de síndrome gripal, baseado na evidência 
que o A/H1N1 pdm era praticamente o único subtipo circulante, o Brasil manteve uma recomendação restritiva de uso que limitou bastante o acesso da população ao medicamento (p. 154).

Em 2010, conforme foi produzida uma ampla campanha de vacinação contra o referido vírus pandêmico (vírus $\mathrm{A} / \mathrm{H} 1 \mathrm{~N} 1 \mathrm{pdm}$ ) "[...] o número de casos graves e de internações hospitalares por pneumonias e influenza foram inferiores ao ano anterior" (LUNA; SILVA JR., 2013, p. 154). Levando em conta essa circunstância apontada pelos autores, é possível considerar que em pandemias anteriores, algumas iniciativas adotadas foram fortemente decisivas para a redução de contaminações e óbitos.

O texto elaborado por Matos (2018) intitulado 'A próxima pandemia: estamos preparados?', publicado em 2018, trouxe para a reflexão "[...] a questão da previsibilidade de uma nova pandemia" (MATOS, 2018, p. 10), alertando que:

[...] a preparação para as situações de emergência, como as pandemias, passam por três etapas essenciais, aprimorando os instrumentos de que dispomos no dia a dia. 1) Aprimoramento da vigilância epidemiológica (...) 2) Pesquisa clínica. (...) 3) Estrutura laboratorial voltada à formação de novos insumos e biológicos (MATOS, 2018, p. 10-11).

Tendo em vista as considerações de Luna e Silva Jr. (2013) e, a reflexão de Matos (2018) acerca da previsibilidade de uma próxima pandemia, o ano de dois mil e vinte (2020) iniciou em meio a uma pandemia, oficializada pela Organização Mundial da Saúde (OMS) em 30 de janeiro de 2020, ocasionado pelo Coronavirus Disease 2019 (COVID-19).

Segundo o relatório situacional do Ministério da Saúde de 08 de abril de 2020, no Brasil existem 15.927 casos confirmados de COVID-19 e 800 óbitos pela doença, tendo o estado de São Paulo como epicentro. Esses dados colocam o Brasil como o terceiro país da Região das Américas com maior número de casos e de óbitos pela doença, atrás dos Estados Unidos e do Canadá (BRASIL, 2020, p. 06).

Com base nessa situação complexa que estamos vivendo no cenário global, o distanciamento social (podendo também progredir para uma quarentena e/ou isolamento social - lockdow $\left.{ }^{6}\right)$, nos coloca enquanto condição humana uma série de questionamentos, modos de organização física e simbólica, tensionando aquilo que já havíamos modulado enquanto sociedade (sistemas de saúde, sistemas de saneamento, sistemas jurídicos, sistemas de ensino, sistema econômico, entre outros).

6 As traduções possíveis para lockdown são restrição de movimento de pessoas ou confinamento social. O sentido original da palavra lockdown é o de manter os presos em suas celas para que seja instaurada a ordem no presídio após rebelião ou tumulto. Também é o termo utilizado em outras situações de emergências em que as pessoas não devem sair de casa para preservar sua segurança, saúde como é o caso de uma pandemia. 
No início, a pandemia apareceu como fenômeno de mídia, situada de modo 'distante' do cenário brasileiro (localizada na Ásia, Europa, entre outros). Não tínhamos ainda a dimensão do que isso iria significar, até que em meados de março chegou de modo 'identificável' no Brasil. Essa onda emergiu com muita força, ocasionando o fechamento de escolas e universidades (públicas e privadas), em seguida das atividades industriais, de construção civil, comerciais, entre outros, que tornaram o distanciamento social uma realidade. No que tange à educação escolar, é preciso pontuar que não tivemos condições de nos prepararmos para o que estava por vir, o que torna a pandemia um acontecimento, uma singularidade em superfície de emergência (FOUCAULT, 2000):

Em todo acontecimento, há de fato o momento presente da efetuação, aquele em que o acontecimento se encarna em um estado de coisas, um indivíduo, uma pessoa, aquele que é designado quando se diz: pronto, chegou a hora; e o futuro e o passado do acontecimento só são julgados em função desse presente definitivo, do ponto de vista daquele que o encarna. Mas há, por outro lado, o futuro e o passado do acontecimento tomado em si mesmo, que esquiva todo presente porque está livre das limitações de um estado de coisas, sendo impessoal e pré individual, neutro, nem geral nem particular, eventum tantum...; ou antes que não tem outro presente senão o do instante móvel que o representa, sempre desdobrado em passado-futuro, formando o que convém chamar de contra-efetuação. Em um dos casos, é minha vida que me parece frágil demais para mim, que escapa num ponto tornado presente numa relação determinável comigo. No outro caso, sou eu que sou fraco demais para a vida, a vida é grande demais para mim, lançando por toda a parte suas singularidades, sem relação comigo nem com um momento determinável como presente, salvo com o instante impessoal que se desdobra em ainda-futuro e já-passado (DELEUZE, 2000, p. 177-178).

Acontecimento que, em Deleuze (1992), pode ser considerado de duas maneiras:

[...] há duas maneiras de considerar o acontecimento, uma consiste em passar ao longo do acontecimento, recolher dele sua efetuação na história, o condicionamento e o apodrecimento da história, mas outra consiste em remontar o acontecimento, em instalar-se nele como num devir, em nele rejuvenescer e envelhecer a um só tempo, em passar por todos os seus componentes e singularidades. O devir não é história; a história designa somente o conjunto das condições, por mais recentes que sejam, das quais desvia-se a fim de "devir", isto é, para criar algo novo (DELEUZE, 1992, p. 211).

Um acontecimento como aquilo que não podemos controlar, toma relevo como uma chance para entrarmos em contato com ele. Transformá-lo em nosso acontecimento, para tirarmos os melhores efeitos dele, mesmo que por vezes, esses efeitos pareçam não existir. Levando em consideração o intento em pensar como essa circunstância tem reverberado 
no âmbito da vida e sua relação com a educação escolar, o presente estudo toma corpo resultante de um empenho de pesquisa, investigação e escrita ${ }^{7}$.

A pesquisa teórico-empírica de caráter qualitativo (DENZIN; LINCOLN, 2006) foi esboçada por meio de um instrumento que é o formulário online, disponibilizado por meio das redes online de pesquisadores ${ }^{8}$, construído a partir da plataforma Google Docs ${ }^{9}$. Esse formulário conta com um conjunto de quinze (15) questões: onze (11) de múltipla escolha, caracterizando perguntas fechadas e, quatro (4) descritivas, caracterizando perguntas abertas. Teve como objetivo coletar informações e percepções ${ }^{10}$ que se tramam com a seguinte problematização 'O que pode a educação escolar em tempos de pandemia de COVID-19?' .

Os achados da pesquisa, serão explorados nesse manuscrito por meio de análise de conteúdo (BARDIN, 2004), tendo como inspiração teórica e epistemológica os escritos de Deleuze (2000; 1992), Guattari e Rolnik (1996), Rolnik (2018), Foucault (2000; 2008), Rouvroy e Berns (2010; 2015) e Corrêa (2006). Inicialmente, apontamos as principais perspectivas e conceitos que serão utilizados como horizonte de compreensão para a atenção teórica das respostas obtidas pelo formulário online. Em seguida, realizamos a pré-análise das respostas produzidas pelos participantes da pesquisa. Após, compilamos os principais achados da pesquisa, constituindo, na sequência, tramas conceituais que nos permitem descrever, analisar, estabelecer relações e aprofundamentos que permitam pensar a educação escolar em tempos de pandemia. Por fim, estabelecemos um apanhado dos principais achados da investigação, constituindo ponderações e possibilidades.

\section{TRAMANDO CONCEITOS E PERSPECTIVAS}

Para pensarmos acerca dos modos como têm acontecido as práticas educacionais diante da pandemia, nos inspiramos no que escrevem Rouvroy e Berns (2010), quando refletem e problematizam acerca das práticas de categorização e perfilação fornecidos pelo que chamam de tecnologias digitais. $\mathrm{O}$ escrito dos autores viabiliza pensarmos o quanto temos vivido uma digitalização da própria vida, no sentido de estarmos sendo, cada vez mais, controlados por dispositivos de detecção, classificação e orientação de comportamentos (ROUVROY; BERNS, 2010). Além disso, os autores ainda consideram que "[...] um poder

7 "Escrever é uma experiência de transformação metamórfica" (STENGERS, 2017, p. 10).

8 Distribuição do link por e-mail, grupos de Whatsapp e grupos da plataforma do facebook. Distribuição que viabilizou um alcance alto de pessoas para que efetuassem o preenchimento do formulário.

9 As ferramentas do Google Docs funcionam de forma síncrona e assíncrona, portanto, on-line para acessar dados em nuvens e off-line através de aplicativos de extensão instalados diretamente do google, onde há bancos de dados criados por essa extensão. E permite aos usuários criar e editar documentos online ao mesmo tempo colaborando em tempo real com outros usuários.

10 Tivemos como público-alvo do questionário, sujeitos implicados e que tenham relação com a instituição escolar, sejam eles: professores/as, estudantes da educação básica e ensino superior e, ao mesmo tempo, pais e/ou responsáveis destes estudantes. 
que reside nos algoritmos de correlação estatística, articulado para um 'controle' ou mais ainda, uma antecipação de um novo tipo nas sociedades 'digitais'" (ROUVROY; BERNS, 2010, p. 88-89), tem atravessado cada vez mais nossas escolhas e práticas, bem como as instituições e conjecturas socialmente estabelecidas. Nesse sentido, todos os agentes que põem em fluxo os engendramentos educacionais (professores/as, gestores/as educacionais, estudantes, entre outros), são deveras afetados e, produzem afetações pela via desse 'controle' que apontam Rouvroy e Berns (2010). Ao passo que essa concepção, vem ao encontro do que escrevem Guattari e Rolnik (1996) quando "[...] usando da linguagem da informática, é que, evidentemente, um indivíduo sempre existe, mas apenas enquanto terminal; esse terminal individual se encontra na posição de consumidor da subjetividade" ( $p$. 32), como um consumidor do que os autores chamam de "[...] sistemas de representação, de sensibilidade, etc." (GUATTARI; ROLNIK, 1996, p. 32). Sistemas, como parte de uma subjetividade capitalística, a qual nos bombardeia, permanentemente "[...] por imagens de mundo e narrativas - o que se agrava com sua proliferação robótica que as multiplicam ao infinito -, as quais tornam seus já efêmeros contornos ainda mais rapidamente caducos" (ROLNIK, 2018, p. 78).

Em relação a isto, o que Rouvroy e Berns (2010) denominam de 'governamentalidade ${ }^{11}$ algorítmica' toma relevo como uma possibilidade de "[...] tornar-se a si mesmo seu próprio perfil automaticamente atribuído e evolutivo em tempo real" (ROUVROY; BERNS, 2015, p. 42), o que abriria mão de transitarmos pelas referências do homem médio (relações presenciais entre pessoas e grupos, entre outros) e, ao mesmo tempo, de pensarmos necessariamente em uma noção de governamentalidade com características disciplinares e liberais, que consomem subjetividades, como pensou Michel Foucault (2008). Nesse sentido, o que aparece é a adesão automática que Rouvroy e Berns (2015) sugerem as práticas contemporâneas. Logo, é possível compreender que:

\footnotetext{
A governamentalidade algorítmica não produz qualquer subjetivação, ela contorna e evita os sujeitos humanos reflexivos, ela se alimenta de dados "infraindividuais" insignificantes neles mesmos, para criar modelos de comportamento ou perfis supraindividuais sem jamais interpelar o sujeito, sem jamais convocá-lo a dar-se conta por si mesmo daquilo que ele é, nem daquilo que ele poderia se tornar. É que a governamentalidade algorítmica, por sua perfeita adaptação ao "tempo real", sua "viralidade" (quanto mais dela se serve, mais o sistema algorítmico se refina e se aperfeiçoa, uma vez que toda interação entre o sistema e o mundo se traduz por um registro de dados digitais, um enriquecimento correlativo da "base estatística" e uma melhoria das performances dos algoritmos), sua plasticidade, torna a própria noção de "falha" insignificante: a "falha" não pode, em outros termos, colocar o sistema em "crise", ela é imediatamente reassimilada a fim de refinar ainda mais os modelos ou perfis de comportamento (ROUVROY; BERNS, 2015, p. 42).
}

11 Noção que constroem a partir da leitura do conceito de 'governamentalidade' produzido por Michel Foucault. Como encontro entre técnicas de dominação e técnicas de si. 
Nesse sentido, traços digitais passam a produzir 'perfis' - traços de subjetividades capitalísticas (ROLNIK, 2018) - tornadas individuais, consumíveis, captadas. No que tange à educação escolar, esses 'perfis' intensificam estratégias de individualização, assinalando o que Rouvroy e Berns (2015, p. 44) chamam de "[...] um processo de dissipação das condições espaciais, temporais e linguísticas da subjetivação e da individuação em benefício de uma regulação objetiva, operacional das condutas possíveis", o que vem ao encontro de "[...] acelerar os fluxos - poupando toda forma de "desvio" ou de "suspensão reflexiva" subjetiva entre os "estímulos" e suas "respostas reflexo" (ROUVROY; BERNS, 2015, p. 44). Aí,

[...] o governo algorítmico não apenas percebe o possível no presente, produzindo uma "realidade aumentada", uma atualidade dotada de uma "memória do futuro", mas também dá consistência ao sonho de um "acaso" sistematizado: nosso real teria se tornado o possível, nossas normas querem antecipar, corretamente e de maneira imanente, o possível, o melhor meio sendo certamente apresentar-nos um possível que nos corresponda e para o qual os sujeitos só precisariam deslizar (ROUVROY; BERNS, 2015, p. 48).

Essa perspectiva que pensa as estatísticas e dados oriundos das tecnologias digitais, já foi deveras discutida por Corrêa (2006) em seu livro 'Educação, comunicação, anarquia: Procedências da sociedade de controle no Brasil'. Na obra, abordou uma aproximação entre educação e comunicação, como "[...] um conjunto coerente de saber e de estratégias de poder para a produção das subjetividades apropriadas ao controle" (CORRÊA, 2006, p. 13). Para Corrêa (2006):

Obter por meio da educação escolar, combinada com as tecnologias de comunicação, o máximo possível de uniformidade e com isso fortalecer o governo. Os universais do bem comum, da paz mundial, da obediência às leis conectam-se à individualidade de cada agente do processo educacional através das práticas educativas (p. 16).

Com a concepção de Corrêa (2006) é possível considerarmos que as instituições conseguem atuar individualmente, pela modulação axiomática dos fluxos, sobre os corpos, reverberando sobre o corpo social e o corpo nação. Em se tratando das tecnologias de comunicação e da governamentalidade algorítmica (ROUVROY; BERNS, 2010, 2015) - situada no campo escolar (inclusive na pandemia de COVID-19) -, têm-se, ao mesmo tempo, uma premissa subjetivadora de evolução/progresso, já que "Seguir na direção do progresso é viabilizar uma utilização eficiente, mais veloz e uniformizadora, dos veículos de massa para o desenvolvimento econômico" (CORRÊA, 2006, p. 94).

Em se tratando de um contexto globalizado marcado pela situação pandêmica de COVID-19, que afeta e produz atravessamentos diretos à situação de saúde das pessoas, 
toma corpo a emergência de um sentimento de comoção geral - a necessidade do desenvolvimento de atividades escolares no formato remoto. Sentimento que, acoplado a uma série de relações de forças e agenciamentos, institui uma reformulação do aparelhamento e operacionalização de uma série de instituições, inclusive aquelas que tratam diretamente da educação escolar de crianças, jovens e adultos, como é o caso das instâncias escolarizadoras no Brasil. Como escreve Corrêa (2006), é a partir de um sentimento dessa natureza "[...] que se pode proceder à fase de individualização, de tratamento das diferenças e de posterior encaminhamento dessas diferenças para uma uniformidade" (p. 109) o que também pode ser entendido como atenção dada às diferenças individuais "[...] de mobilização para o consenso" (CORRÊA, 2006, p. 110). Em Rolnik (2018), trata-se de um "[...] modo de subjetivação que nele se produz o que lhe confere sua consistência existencial, sem a qual ele não se sustentaria; um não vai sem o outro" (p. 35).

Quando as tecnologias de comunicação e tecnologias digitais operam como principais vetores da educação escolar na pandemia, podem vir a produzir "[...] ações pedagógicas voltadas para o indivíduo, para a individualização, para o assujeitamento" (CORRÊA, 2006, p. 125), ao passo que "Com ele a individualidade entra num campo documentário de pequenas técnicas de registro, anotação e constituição de processos" (CORRÊA, 2006, p. 125).

Há, nesse contexto remoto, uma ampliação do modo operante que inspeciona/controla "[...] o que cada aluno produz individualmente" (CORRÊA, 2006, p. 129), sendo a comunicação o fator que "[...] constitui o regime de celas em que somos individualmente colocados em contato com as mensagens, com as informações" (CORRÊA, 2006, p. 152). Aparece aí, tanto nos estudantes, quanto nos professores/as, instâncias subjetivas que, pela via do controle do funcionamento das engrenagens individuais e coletivas, instauram uma série de afetos que, hora ou outra, produzem a sensação de culpabilização das pessoas. É sobre isso que Rolnik (2018) escreve:

A raiz das tecnologias capitalísticas de culpabilização consiste em propor sempre uma imagem de referência a partir da qual colocam-se questões tais como: "quem é você?", "você que ousa ter uma opinião, você fala em nome de quê?", "o que você vale na escala de valores reconhecidos enquanto tais na sociedade?", "a que corresponde sua fala?", "que etiqueta poderia classificar você?" E somos obrigados a assumir a singularidade de nossa própria posição em o máximo de consistência. Só que para isso é frequentemente impossível de fazermos sozinhos, pois uma posição implica sempre um agenciamento coletivo. No entanto, à menor vacilação diante dessa exigência de referência, acaba-se caindo, automaticamente, numa espécie de buraco, que faz com que a gente comece a se indagar: "afinal de contas quem sou eu? Será que sou uma merda?" É como se nosso próprio direito de existência desabasse. $\mathrm{E}$ aí se pensa que a melhor coisa que se tem a fazer é calar e interiorizar esses valores. Mas quem é que diz isso? Talvez não seja necessariamente o professor, ou o mestre explícito exterior, mas sim algo de nós mesmos, em nós mesmos e que nós mesmos reproduzimos (p. 40-41). 
Essa articulação que, por vezes produz uma culpabilização, aparece com Rolnik (2018) como um dos tantos modos que fabricam as relações dos sujeitos consigo mesmos, pela via da automodelação, do autogoverno. O que caracteriza boa parte das sensações, efeitos, atravessamentos que têm modulado existências, inclusive na escolarização se deslocarmos o pensamento para as ações educativas desenvolvidas em tempos de pandemia.

Tendo isso em vista, tomamos os escritos dos autores supracitados como inspirações teóricas e epistemológicas desse estudo, no sentido que nos fornecem subsídios para a produção de uma série de relações e aprofundamentos em suspensão que nos permitam pensar os atravessamentos da pandemia de COVID-19 na educação escolar brasileira.

Contingência que, cada vez mais, tem demandado dos/as professores/as a operacionalização de uma pedagogia que ponha em movimento premissas "[...] máquinas técnicas (...) máquinas sociais, máquinas estéticas, máquinas teóricas e assim por diante" (ROLNIK, 2018, p. 239) que põe em funcionamento ações ora denominadas não presenciais, ora remotas, ora de Educação a Distância (EAD).

\section{ANÁLISE DOS ACHADOS E DISCUSSÕES}

O formulário online, ferramenta utilizada para coleta dos dados, ficou disponível para recebimento de respostas no intervalo de sete (7) dias ${ }^{12}$. Nesse período, contabilizamos o total de cento e cinquenta (150) respondentes. No que diz respeito às respostas obtidas, mantivemos e continuaremos mantendo o sigilo de identificação durante todo o processo de análise dos dados, o que nos demanda identificá-los, utilizando como estratégia as letras que compõem o alfabeto (Sujeito A, Sujeito B, Sujeito C, e assim por diante).

Inicialmente, realizamos uma pré-análise das respostas coletadas por meio do formulário online. Partindo dessas análises iniciais, compilamos as respostas que, de modo geral, apresentam elementos pertinentes de serem abordados na pesquisa, tendo em vista que materializa um corpus de investigação que atravessa a educação escolar.

Face ao exposto, dentre as perguntas introdutórias presentes no formulário online, estava a que indagava acerca da faixa etária dos sujeitos. Conforme apresenta Figura 1 a seguir, a maioria dos respondentes, setenta e nove (79) encontra-se entre trinta e um (31) e cinquenta (50) anos de idade. 
Figura 1 - Gráfico da faixa etária dos respondentes.

\section{Qual sua faixa etária?}

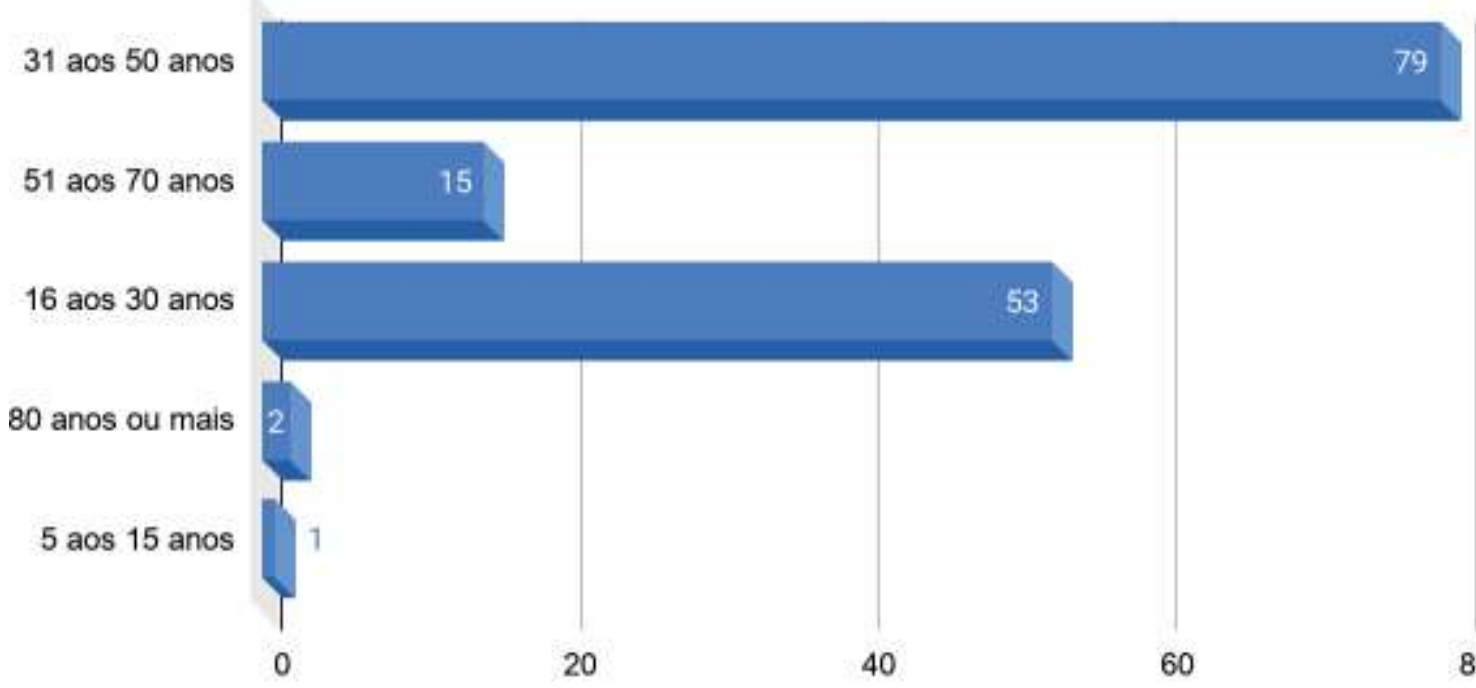

Número de respondentes

Fonte: Dados dos pesquisadores (2020).

Ao passo que, do total de respondentes, cento e dezenove (119) são do sexo feminino e, apenas trinta e um (31) do sexo masculino. Conforme tem circulado em alguns websites, como é o caso do 'Papo sobre autoestima', verificamos na reportagem construída pela colunista Carla Pepe que, acerca das mulheres na quarentena "[...] muitas retornaram integralmente ao espaço da casa, com todas as tarefas que Ihe são atribuídas: trabalho remoto, supervisionar as lições das crianças, fazer as tarefas domésticas" (PEPE, 2020). Nesse sentido, tendo em vista a concepção de Pepe (2020), podemos ponderar que o número expressivo de mulheres respondentes do formulário online, pode estar vinculado a essa constatação.

Quanto ao nível de escolaridade dos respondentes, verificamos que: quarenta e cinco (45) destes possuem algum curso de Especialização; vinte e quatro (24) possuem curso Superior incompleto ou em andamento; vinte (20) possuem curso de Mestrado; e dezesseis (16) possuem título de Doutorado. Conforme é possível verificarmos na Figura 2 a seguir: 
Figura 2 - Gráfico do nível de escolaridade dos respondentes.

\section{Qual seu nivel de escolaridade?}

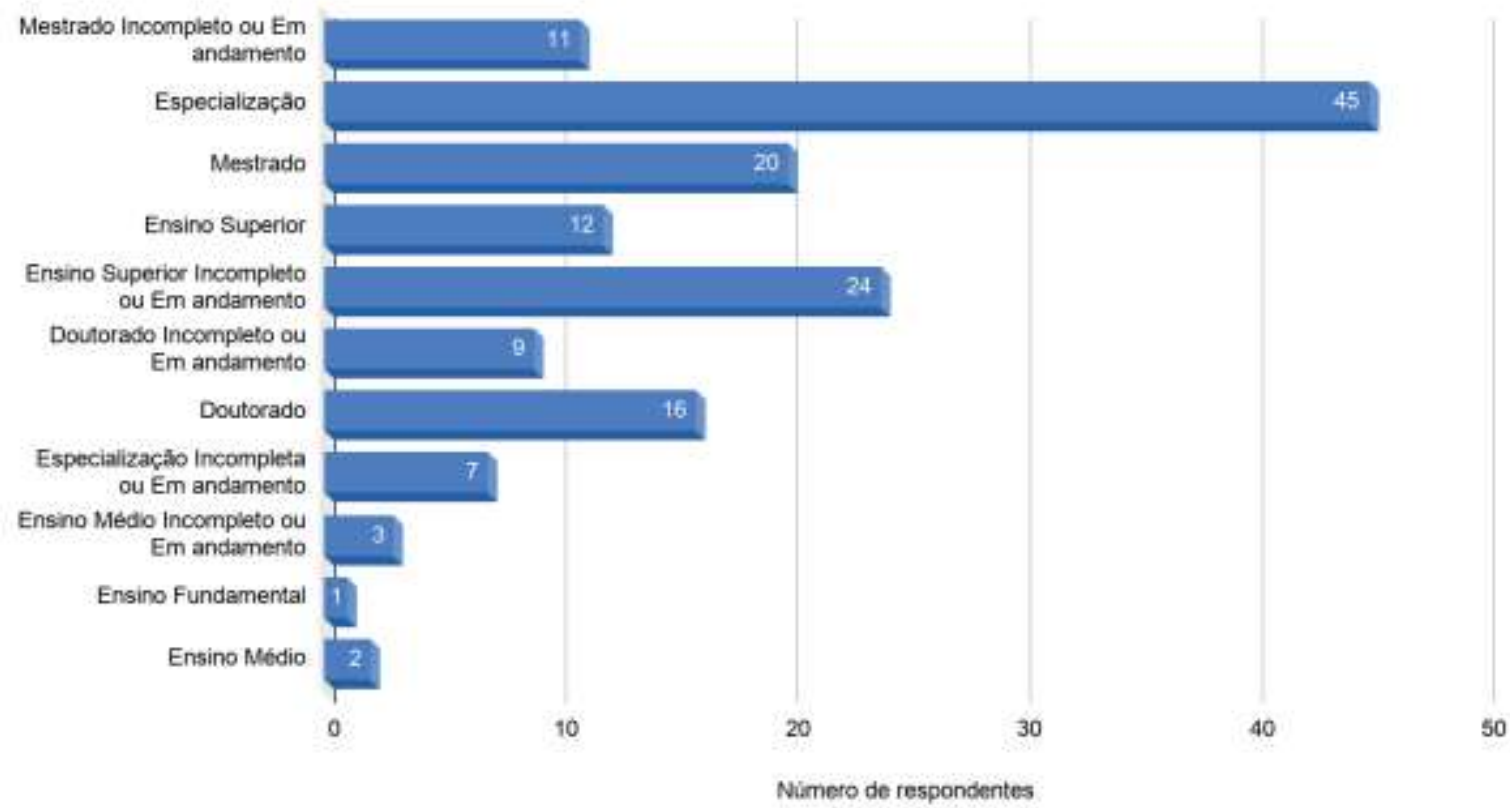

Fonte: Dados dos pesquisadores (2020).

Os dados do gráfico permitem considerarmos que apenas seis (6) respondentes situam-se no âmbito de formação até o nível médio (Educação Básica). O que vem ao encontro de considerar que o público-alvo que atingimos com a pesquisa é, consideravelmente, de indivíduos com alguma formação em nível Superior (incompleto, em andamento ou concluído) e/ou Pós-graduação (lato sensu - strictu sensu).

Ao passo que, dos respondentes: $61,33 \%$, ou seja, noventa e dois (92) estudaram em instituições públicas durante a trajetória escolar; seguidos por 29,33\% (quarenta e quatro (44) que estudaram em instituições privadas e públicas; e apenas 9,33\% (quatorze (14) que estudaram apenas em instituições privadas durante a trajetória escolar. Dado que permite ponderarmos que, $90,66 \%$ dos respondentes, já teve algum tipo de contato escolar com instituições de caráter público durante a trajetória escolarizadora.

A localização geográfica dos respondentes ficou majoritariamente situada na região Sul do Brasil (Santa Catarina, Rio Grande do Sul e Paraná), totalizando cento e trinta e dois (132); seguida pela região Sudeste (São Paulo, Rio de Janeiro, Minas Gerais e Espírito Santo), totalizando dez (10) respondentes. A região que menos alcançou respostas foi a região Norte (Acre, Amapá, Amazonas, Pará, Roraima, Rondônia e Tocantins), totalizando apenas um (1) respondente. A região Nordeste não foi contemplada, justamente pelo fato de que não houve nenhum respondente dessa territorialidade. $O$ número significativo de respondentes na região Sul, provavelmente encontra-se situado no compartilhamento sig nificativo do formulário online entre nossos pares, o que pode ter contribuído para que os sujeitos se sentissem motivados para responder o mesmo. 
Em se tratando da pergunta descritiva: Como você tem se sentido em relação à Pandemia que estamos vivendo?, recebemos uma multiplicidade de sentimentos e também modos de lidar com a circunstância atual. Alguns sujeitos, como é o caso do Sujeito A estão "sentindo falta do trabalho e dos amigos. Gosto de estar em casa com minha família". Outros, estão sentindo "Preocupação e medo. É algo terrível, pessoas estão morrendo sem receber atendimento, as famílias não podem nem enterrá-los. A quarentena também é complicado, mas necessário, devemos ficar longe das pessoas que amamos para preveni-las de algo pior" (Sujeito B).

Do mesmo modo, como identificamos que boa parte dos respondentes são oriundos de programas de pós-graduação, toma relevo o sentimento de preocupação "[...] principalmente no que se refere à formação docente na área após entrada total da EAD (propiciada sob argumento da pandemia)" (Sujeito C); ao mesmo tempo em que aparece o sentimento de culpa "[...] não tenho conseguido realizar todas as atividades das aulas e as leituras para a pesquisa, o que faz me sentir culpado" (Sujeito N). Tendo como fio com relevo essas respostas, aparece um trato quase que unânime dos respondentes, quanto às atividades educacionais que têm acontecido na pandemia caracterizadas como se todas fossem EAD. Por sua vez, embora aparentemente todas as estratégias que estejam sendo empregadas se assemelham a EAD, ao atentarmos para o que temos visto acontecer, podemos ponderar a existência de: atividades não presenciais (realizadas sem a presença física do estudante no ambiente escolar, podendo haver, ou não, a relação professor-aluno de modo virtual); atividades remotas (considerada uma solução temporária/emergencial para que as atividades educativas continuem acontecendo, tendo a internet como principal ferramenta - geralmente por meio da gravação de videoaulas, envio de atividades ou roteiros de estudos dos livros didáticos, mantendo a figura do professor/a, a partir de dias e horários que contemplam premissas do ensino presencial); EAD (modalidade com funcionamento próprio que pressupõe apoio de tutores, concepção didático-pedagógica, utilizando-se de carga horária específica, por meio do uso de diferentes recursos e atividades - na maioria dos casos de modo atemporal, flexível).

As atividades docentes que estão sendo desenvolvidas de modo emergencial nesse cenário, portanto, aparecem como um desafio que opera pela via do alargamento de sentimentos de ansiedade, angústia, culpabilização. Embora reconheçamos que existe, por exemplo, uma história recente já trilhada acerca da modalidade EAD no Brasil, verificamos que pelo menos a educação escolar e superior pública, ainda não havia dado tanta ênfase a discussões envolvendo-a, bem como as múltiplas estratégias e plataformas a serem utilizadas em atividades remotas (emergenciais). Por sua vez, em se tratando das instituições privadas de educação básica e superior verificamos uma ênfase significativa no que tange ao trato com a modalidade EAD, e atividades remotas. Sabendo que com a EAD, por exemplo, é possível realizar uma economia de investimento e um retorno financeiro mais rapidamente, essa modalidade acaba prevalecendo com maior força no ínterim das insti- 
tuições privadas, como uma forma de maximizar os retornos financeiros dos investimentos. Aí, encontramos um fator que coloca a presença de atividades remotas e, por vezes a EAD nas instituições públicas como uma realidade, de certa forma, compulsória, tendo em vista o acontecimento ocasionado pela pandemia. Em contrapartida, nas instituições privadas, vimos o trato com essas questões acontecerem de modo mais sincronizado, já que as mantenedoras já vinham adotando tal modalidade e, ao mesmo tempo atividades remotas e não presenciais, como estratégias para o ensino - como forma de maximizar os retornos financeiros dos investimentos ${ }^{13}$.

Na sequência, o escrito do Sujeito $D$ sinaliza uma preocupação quanto à educação escolar "Me sinto sendo atirada para todos os lados. Uns exigem que os estudantes precisam continuar estudando (mesmo sem aulas presenciais); outros exigem que paremos, comecemos a pensar acerca dos rumos que estamos tomando em termos escolarizadores". Sua escrita remete a uma preocupação acerca dos rumos da educação escolar, independente do nível, que tem vindo ao encontro de tensionar os paradoxos que contornam a existência de quem habita o referido território - seja professor/a, seja aluno. O que corrobora com o que escreve o Sujeito $E$, no que tange aos sintomas que tem aparecido em meio às estratégias educacionais em tempos de pandemia:

Ansiosa, com dúvidas quanto ao aproveitamento dos alunos sobre as aprendizagens durante as atividades à distância, angustiada com os novos rumos da educação brasileira pós pandemia. Mas motivada e buscando ferramentas e estratégias inovadoras para mediar a aprendizagem nesse tempo. Trabalho com ensino médio (escola pública) e ensino superior (curso de licenciatura, faculdade privada).

Ao passo que esse mesmo sentimento do Sujeito $E$, vem ao encontro de um cansaço, descrito pelo Sujeito F:

Extremamente cansada, pois o trabalho EAD tem exigido muito e, ao mesmo tempo, estou cuidando dos meus sobrinhos que não têm onde ficar. Então estou tendo que administrar o trabalho em casa +2 sobrinhos de 2 e 4 anos, extremamente dependentes e agitados. Me sinto culpada por não conseguir fazer o melhor sempre.

Nesse sentido, tendo em vista uma análise de conteúdo (BARDIN, 2004) verificamos que a maioria dos sentimentos descritos pelos respondentes fica situado nesse âmbito que prolifera sensações de ansiedade, medo, angústia, apreensão e culpa. Em contraponto, poucos respondentes apresentam alguns horizontes possíveis que aparecem como brecha para habitarmos essa pandemia "Estamos num período de tensão, apreensão, ansiedade

$\overline{13 \text { O que não }}$ acontece no âmbito das instituições públicas. 
e outros sentimentos negativos. Contudo, tendo que se redescobrir, reinventar, dar conta de muitas coisas ao mesmo tempo..." (Sujeito G), além do que escreve o Sujeito H "Como sabemos é uma situação que foge a nossa realidade, o discernimento, calma e atenção são medidas necessárias para se enquadrar nessa realidade. Tenho procurado seguir as orientações, é algo novo para todos".

Quando perguntados 'Antes da Pandemia, você já utilizava ambientes virtuais e/ou ferramentas tecnológicas digitais?' obtivemos os seguintes resultados: cento e trinta e oito (138) sujeitos (92\%) responderam que sim, que já utilizam ambientes virtuais e/ou ferramentas tecnológicas digitais e, doze (12) dos respondentes (8\%) afirmam que não, que não utilizam tais ambientes e/ou ferramentas.

Com intuito de compreendermos com maior profundidade a resposta, incluímos uma pergunta que tratava especificamente do uso dos ambientes virtuais e/ou ferramentas tecnológicas digitais utilizados como estratégia educacional. Nessa pergunta, obtivemos os seguintes resultados: $70 \%$ afirmaram já fazer uso desses espaços/modalidades para fins educacionais; 30\% afirmaram não terem feito uso desses espaços/modalidades para fins educacionais. Ao analisarmos as respostas, tomou relevo a compreensão de que, embora a maioria dos respondentes já tenha algum curso em nível Superior (concluído ou em andamento), 30\% selecionaram a opção que indica não terem feito uso desses espaços/ modalidades para fins educacionais. O que corrobora para que percebamos que, em certa medida, o público-alvo majoritário da pesquisa não havia tido experiências educacionais por meio de ambientes virtuais e/ou ferramentas tecnológicas digitais.

A pergunta 'Você se considera preparado para desenvolver suas ações de aprendizagem de modo remoto através dos ambientes virtuais de aprendizagem e/ou plataformas digitais?' resultou nas seguintes respostas: $56 \%$ selecionaram a opção 'em parte', 24\% a opção 'sim' e, 20\% a opção 'não'. Ao atentarmos para as respostas, podemos verificar que a minoria dos respondentes se consideram 'não' preparados para desenvolver suas ações de aprendizagem de modo remoto através dos ambientes virtuais de aprendizagem e/ou plataformas digitais. Por sua vez, se atrelarmos esses sujeitos aos que selecionaram 'em parte', contabilizamos um total de $76 \%$ de pessoas que não se consideram totalmente preparados para atividades deste fim. Levando em conta que a maioria dos respondentes possui, no mínimo, acesso à formação em nível Superior (incompleto, em andamento ou concluído), os dados nos levam a ponderar que, a utilização demasiada dessas estratégias pela via de ambientes virtuais de aprendizagem e/ou plataformas digitais não aparece como uma atitude vista como favorável no que tange ao preparo dos sujeitos respondentes da pesquisa.

Para alargarmos a compreensão acerca da resposta anterior, a pergunta subsequente foi a seguinte 'Caso você sinta alguma dificuldade quanto ao uso de plataformas digitais para fins educacionais poderia compartilhar conosco? Descreva'. As respostas obtidas foram múltiplas, por sua vez, destacamos as seguintes: 
Grande parte dos alunos não possui acesso a internet dificultando o acesso as aulas. E a parte que possui está desinteressada em continuar os estudos desta forma. (Sujeito I).

Acredito que em relação às plataformas, estou mais tranquila, fomos orientados e apresentados à elas. A maior dificuldade é o material para preparar nossas aulas, como câmera, microfone, isolamento acústico... esse é o maior desafio. (Sujeito J). Falta de capacitação sobre a metodologia. (Sujeito $L$ ).

A dificuldade que sinto e cultural em assumir postura de uma educação híbrida. Sem estrutura física das redes lógicas das escolas públicas. Em sua maioria chega a rede de Internet, mas não tem rede lógica de distribuição de qualidade. Fator que dificulta o trabalho docente em trabalhar com muitos alunos no mesmo acesso. (Sujeito M).

As respostas, trazem consigo uma série de forças e especificidades "A dificuldade que encontro diz respeito à falta de diálogo e atenção, no que tange à relação com professores e colegas" (Sujeito $\mathrm{N}$ ); ao mesmo tempo que algumas tratam do modo como tem se organizado as atividades, "Muito bagunçado. É difícil saber o que tenho que fazer e falta flexibilização dos professores quanto aos horários, pois, pra mim, é péssimo cobrar o horário comercial dos alunos sendo que estão todos aflitos e em casa pela pandemia" (Sujeito O). De modo geral, um dos discursos que mais toma ênfase é o seguinte "Não tive nenhuma formação. Fui usando e aprendendo" (Sujeito P), o que corrobora para a compreensão que, a utilização de plataformas digitais para fins educacionais aparece, nesse conteúdo narrativo, como parte de estratégias e 'vontades' individuais. Fato que não é unanimidade nas respostas obtidas na pesquisa, já que alguns afirmam "além do que não tive formação para dar aulas EAD" (Sujeito F).

Tendo em vista a pergunta anterior, também incluímos no formulário online a seguinte pergunta 'Caso você sinta alguma facilidade quanto ao uso de plataformas digitais para fins educacionais poderia compartilhar conosco? Descreva'. Nessa questão, verificamos uma quantidade excessiva de respostas que apontavam para a seguinte resposta "Não tenho facilidade" (Sujeito Q). Por sua vez, também identificamos sujeitos que responderam "Como gosto de produzir conteúdo, tenho facilidade em montar materiais, apresentação e procurar conteúdos" (Sujeito R) e, "Posso realizar as tarefas em qualquer momento" (Sujeito $\mathrm{S}$ ). Com isso, sinalizamos que, embora a maioria dos respondentes tenha apresentado uma série de dificuldades, ainda sim, há pessoas que apresentam facilidades quanto ao uso e manuseio de plataformas digitais para fins educacionais.

Como última pergunta do formulário online, estava 'Caso você pudesse propor alguma solução/alternativa para o que temos vivido, no que tange às estratégias educacionais, qual seria? Descreva'. A referida pergunta teve como intuito realizar um levantamento acerca do que cada um dos respondentes tem pensado, no que tange a soluções e alternativas, para o campo da educação escolar em tempos de pandemia do COVID-19. As respostas circundam uma série de aspectos como: "Orientação e discussões em plataformas digitais" (Sujeito Q); "Maior divulgação das plataformas virtuais, e curso de acesso para os leigos" 
(Sujeito M); "Maior participação escola/família e disponibilização de maior acesso a internet aos estudantes e professores, assim como um treinamento no uso dessas tecnologias" (Sujeito T); "Manter a calma e, na medida do possível, continuar com as atividades rotineiras" (Sujeito U). Por sua vez, algumas das respostas, atravessam diretamente o modo como algumas instituições, constituídas por gestores, técnicos e docentes, têm dado andamento às atividades didático-pedagógicas escolares (com crianças, jovens e adultos).

Conforme o Sujeito V é solução/alternativa "Reavaliar a questão da quantidade de conteúdos que precisa ser repassado aos alunos, trabalhando o essencial, para que assim possa ser focado na aprendizagem com qualidade e não quantidade", o que vem ao encontro do que aponta o Sujeito B quando afirma "Menor ritmo de cobrança". Em certa medida, quando o Sujeito B aponta como solução/alternativa reduzir o ritmo de cobrança, ele sinaliza para um fato que se encontra relacionado com uma série de tarefas e/ou atividades que estão sendo demandadas dele no contexto escolar (de nível básico, superior ou pós-graduação), seja ele estudante ou professor/a. Contingência que serve como um sintoma que aponta para o quanto as estratégias pedagógicas oferecidas pelas instituições de ensino podem estar operando de modo a sobrecarregar os sujeitos envolvidos nos processos escolares (professores/as e/ou estudantes), podendo vir a produzir sentimentos que vão desde o sofrimento psíquico, culpabilização, até outras formas de sofrimento. Ao nosso ver, boa parte desse ritmo de cobrança pode estar vinculado à tentativa de transposição de premissas do ensino presencial, agora em um contexto de ensino não presencial, remoto ou EAD. Uma tentativa emergencial e compulsória que tem agenciado práticas educacionais pouco potentes quanto à produção de espaços de diálogo e troca, evidenciando sintomas de irritação e ansiedade (independentemente de faixa etária). Além, é claro, de uma noção de formação escolar que esteja comprometida com o saber enquanto posse, acúmulo, que pode ser 'obtido' - operando como uma espécie de 'fardo' nos estudantes e/ou professores/ as.

Além dessa ponderação, toma relevo o escrito de Sujeito D:

Não consigo pensar em uma abordagem que não precisasse do contato entre pessoas, uma vez que boa parte dos estudantes da rede pública ainda não tem acesso a meios digitais e a internet, um ensino à distância seria uma alternativa inviável. Assim, talvez a entrega individual de textos explicativos, atividades e trabalhos aos alunos no distanciamento social poderia ser uma alternativa. No entanto, não vejo muitas formas de como alterar essa situação.

A resposta supracitada, dá conta de apresentar o quanto os caminhos que estamos trilhando em termos de estratégias pedagógicas da educação escolar em tempos de pandemia, têm produzido nas pessoas, uma série de confusões, ansiedades, medos, angústias. Além disso, foi possível percebermos que a última pergunta do questionário 'Caso você pudesse propor alguma solução/alternativa para o que temos vivido, no que tange às es- 
tratégias educacionais, qual seria? Descreva', aparece como algo distante dos horizontes dos respondentes, a ponto do que sugere o Sujeito $X$ "Suspensão do calendário acadêmico neste semestre, visto a diversidade de contextos que emergem no cotidiano dos cursos e a dificuldade dos alunos da Educação Básica em acessar e desenvolver atividades remotas".

Desse modo, quando atentamos para a problematização que motivou a construção da pesquisa - 'O que pode a educação escolar em tempos de pandemia de COVID-19?' - é possível considerarmos que, em termos gerais, no que tange ao empreendimento de uma análise acerca das concepções e escritas dos respondentes, o que tem prevalecido é uma série de sensações e afetos que vão ao encontro da culpabilização que Rolnik (2018) explorou e, produz uma série de sintomas psíquicos e físicos nas pessoas que estão de algum a forma vinculadas às instituições de ensino. A pandemia, como acontecimento, tem dado a pensar os modos pelos quais temos nos movimentado no que tange à educação escolar brasileira.

\section{TRAMANDO ALGUMAS CONSIDERAÇÕES FINAIS}

O presente estudo realizou uma pesquisa teórico-empírica de caráter qualitativo (DENZIN; LINCOLN, 2006), esboçada por meio da ferramenta formulário online. O objetivo da pesquisa esteve pautado em coletar informações e percepções que se tramam com a seguinte problematização 'O que pode a educação escolar em tempos de pandemia de COVID-19?'. Os dados coletados foram explorados por meio de análise de conteúdo (BARDIN, 2004), contemplando todas as fases e procedimentos de estudo.

De modo geral, foi possível compreendermos que as experiências resultantes de atividades não presenciais, remotas e na modalidade EAD têm acontecido de modo compulsório, principalmente nas instituições públicas, em meio a uma emergência que trouxe a tona um déficit de repertório que possibilite o desenvolvimento de uma atuação pedagógica mediada pelo computador e/ou dispositivos eletrônicos -, bem como rede de internet disponível, atrelada a um planejamento prévio (com repertório metodológico que contemple essa especificidade).

Resulta do empreendimento de pesquisa o levantamento que aponta para um aumento expressivo de sentimentos como: ansiedade, angústia e medo, tendo em vista o contexto de pandemia. Nosso tempo nessa contingência está sendo cada vez mais ocupado pelas demandas profissionais, agora no contexto privado das casas. Nota-se, a partir disso, que a realização de atividades escolares, assim como desenvolvíamos presencialmente nas escolas, têm operado como gatilhos de crises de ansiedade, os quais reverberam para produção de sofrimento e, até mesmo de culpabilização no âmbito da educação escolar no distanciamento social.

A maioria dos respondentes que atingimos com a pesquisa possui alguma formação em nível Superior (incompleto, em andamento ou concluído) e/ou Pós-graduação (lato 
sensu - strictu sensu). Além disso, em sua maioria são oriundos do sexo feminino, o que nos permite apontar que, no universo dessa pesquisa, as mulheres parecem ter sido mais fortemente afetadas pelos caminhos que temos trilhado, em termos de estratégias de configuração educacional, em tempos de pandemia, o que reforça as ponderações já apontadas por Pepe (2020).

Embora reconheçamos que ainda estamos experimentando os primeiros traços de pesquisa desse acontecimento em nossa sociedade, encontramos nessa investigação um importante repertório que contribui para que atentemos às múltiplas relações de forças que têm nos produzido enquanto agentes que alimentam a engrenagem de funcionamento da educação escolar brasileira.

Resultou da pesquisa a compreensão da pandemia como um acontecimento (DELEUZE, 1992; 2000), que emerge em meio a um cenário de governamentalidade algorítmica (ROUVROY; BERNS, 2010), o qual vincula-se a um agenciamento de subjetividade capitalística (ROLNIK, 2018). Com isso, a pandemia colocou em ênfase esse movimento de controle, individualização e comunicação (CORRÊA, 2006) que já tínhamos como elementos de uma engrenagem neoliberal, o qual, visto sob o prisma da educação escolar, vem produzindo ainda mais afetos, efeitos e sintomas sob as vidas e corpos das pessoas vinculadas, de algum modo, às instituições de ensino. $O$ quanto as estratégias de ensino empregadas em tempos de pandemia têm contribuído para um aumento massivo de sofrimento psíquico, em meio a um contexto de distanciamento social, já que boa parte delas utilizam premissas do ensino presencial. 


\section{REFERÊNCIAS}

BARDIN, L. Análise de conteúdo. Lisboa: Edições 70, 2004.

BRASIL. Ministério da Saúde. Diretrizes para Diagnóstico e Tratamento da COVID-19 - Versão 2, 2020. Disponível em: https://portalarquivos.saude.gov.br/images/pdf/2020/April/13/DiretrizesCO- VID-13-4.pdf. Acesso em: 21 abr. 2020.

CARVALHEIRO, J. R. Epidemias em escala mundial e no Brasil. Revista Estudos Avançados, v. 22, n. 64, dez., p. 7-17, 2008.

CORREAA, G. C. Educação, comunicação, anarquia: procedências da sociedade de controle no Brasil. São Paulo: Editora Cortez, 2006.

DELEUZE, G. Conversações. São Paulo: Editora 34, 1992.

DELEUZE, G. Lógica do sentido. São Paulo: Perspectiva, 2000.

DENZIN, N. K. e LINCOLN, Y. S. Introdução: a disciplina e a prática da pesquisa qualitativa. In: DENZIN, N. K. e LINCOLN, Y. S. (Orgs.). O planejamento da pesquisa qualitativa: teorias e abordagens. 2. ed. Porto Alegre: Artmed, 2006. p. 15-41.

FOUCAULT, M. Em Defesa da Sociedade. São Paulo: Editora Martins Fontes, 1999.

FOUCAULT, M. Nietzsche, a genealogia, a história. In: MOTTA, M. B. (Org.). Arqueologia das ciências e história dos sistemas de pensamento. Rio de Janeiro: Forense Universitária, 2000.

FOUCAULT, M. Segurança, Território, População. São Paulo: Martins Fontes, 2008.

GUATTARI, F; ROLNIK, S. Micropolítica: Cartografias do Desejo. Petrópolis: Vozes, 1996.

LUNA, E. J. A.; SILVA JR., L. J. B. Doenças transmissíveis, endemias, epidemias e pandemias. In: FUNDAÇÃO OSWALDO CRUZ. A saúde no Brasil em 2030 - prospecção estratégica do sistema de saúde brasileiro: população e perfil sanitário [online]. Rio de Janeiro: Fiocruz/lpea/Ministério da Saúde/Secretaria de Assuntos Estratégicos da Presidência da República, v. 2, p. 123-176, 2013.

MATOS, H. J. A próxima pandemia: estamos preparados? Revista Pan-Amazônica de Saúde, v. 9, n. 3, p. 9-11, 2018.

STENGERS, I. Reativar o animismo. Tradução Jamille Pinheiro Dias. Belo Horizonte: Chão de Feira, 2017.

PEPE, C. A sobrecarga feminina em tempos de quarentena e coronavírus. 2020. Disponível em: https://f-utilidades.com/2020/04/02/a-sobrecarga-feminina-em-tempos-de-quarentena-e-corona-virus/ Acesso em: 22 abr. 2020.

ROLNIK, S. Esferas da Insurreição: notas para uma vida não cafetinada. São Paulo: n-1 edições, 2018. 
ROUVROY, A; BERNS, T. Le nouveau Pouvoir Statistique: ou quand le controle s'exerce sur un réel normé, docile et sans événement car constitué de corps "numériques". Multitudes, n. 40, p. 88-103, 2010. Disponível em: https://periodicos.pucpr.br/index.php/aurora/article/view/25304/24163. Acesso em: 22 abr. 2020.

ROUVROY, A; BERNS, T. Governamentalidade algorítmica e perspectivas de emancipação: o díspar como condição de individuação pela relação? Revista Eco Pós, Tecnopolíticas e Vigilância, v. 18, n. 2, 2015. 